\title{
Continuous octreotide infusion for treatment of upper gastrointestinal bleeding due to portal hypertension in children: An observational study from pediatric intensive care unit
}

\author{
P.B. Koul ${ }^{\mathrm{a}, *}$, B.R. Totapally ${ }^{\mathrm{b}}$ and A. Raszynski ${ }^{\mathrm{b}}$ \\ ${ }^{\mathrm{a} D i v i s i o n}$ of Pediatric Critical Care Medicine, Department of Pediatrics, College of Medicine, \\ University of Florida, and Wolfson Children Hospital, Jacksonville, FL, USA \\ ${ }^{\mathrm{b}}$ Division of Critical Care Medicine, Miami Children's Hospital, Miami, FL, USA
}

Received 3 September 2010

Revised 12 January 2011

Accepted 28 February 2011

\begin{abstract}
Evaluate the usage of octreotide for the control of acute upper gastrointestinal bleeding in children with portal hypertension. A retrospective electronic database analysis of these children was performed over a period of five years. Setting was a tertiary pediatric intensive care. Case notes of 18 encounters in 13 children were reviewed. A loading dose $(1.27 \pm 0.76 \mu \mathrm{g} / \mathrm{kg})$ was administered in seven, with median starting dose of $1.44 \pm 1.19 \mu \mathrm{g} / \mathrm{kg} / \mathrm{h}$ in all other episodes. The mean maximum dose was $1.68 \pm 1.38 \mu \mathrm{g} / \mathrm{kg} / \mathrm{h}$. Re-bleeding occurred in one third; hemostasis was eventually achieved in all. Octreotide infusion appears to be safe and effective in controlling pediatric upper gastrointestinal bleeding due to portal hypertension. We also recommend its use in community and rural hospital settings prior to transfer of such patients to a tertiary care center.
\end{abstract}

Keywords: Upper gastrointestinal bleeding, children, PICU, octreotide

\section{Introduction}

Severe upper gastrointestinal (UGI) bleeding in children is a relatively uncommon but life threatening complication of portal hypertension. The mortality rate in adults with UGI bleeding is reportedly in range of $4 \%$ to $9 \%$ [1]. In adult patients with acute UGI bleed, the hemostatic efficacy of octreotide has been well documented, and proven comparable to sclerotherapy [2-4].

*Corresponding author: Pulin B. Koul, 3rd Floor, 800 Prudential Drive, Jacksonville, FL, USA 32207. E-mail: kidscritcare@ hotmail. com.
Children with UGI bleeding who may not be suitable candidates for major invasive interventions, such as endoscopic sclerotherapy, angiographic embolization or shunt surgery, are a therapeutic challenge, may benefit from continuous octreotide infusion.

Octreotide, the first synthetic somatostatin analogue, has four amino acids in common with native somatostatin necessary for its biological function. It has a half-life of 1 to 2 hours, with therapeutic effects lasting up to 6 hours [2]. Octreotide acts by decreasing the portal pressure, the hepatic wedge pressure and azygous blood flow $[1,3]$. The drug may be effective because it increases splanchnic arteriolar resistance, 
while inhibiting the hormones involved in vasodilatation [5], and may possess gastrointestinal cytoprotective properties as it suppresses the gastric parietal cell acid secretions [6]. The use of octreotide to control UGI bleed in pediatric literature has been infrequently documented [6-9]. In this paper, we present our experience with a series of 18 episodes in 13 patients, admitted with severe UGI bleed due to portal hypertension and review its use in pediatric literature so far.

\section{Materials and methods}

After approval by institutional review board; the hospital pharmacy electronic database identified the patients, who had received octreotide, during a 5-year period. Subsequently, the pediatric intensive care unit [PICU] electronic database was used to retrieve the complete files of these patients. The clinical information retrieved included: the age, gender, weight, presenting complaints, diagnosis, hemodynamic parameters, imaging studies, tissue diagnosis, past history of invasive procedures such as sclerotherapy or embolization, prior $\mathrm{H} 2$ blocker or proton pump inhibitor use, and volume of red cell replacement infused prior to and during the PICU stay. While complete laboratory data was retrieved and reviewed, pertinent data is placed in table 1 . The dose and the duration of octreotide therapy were recorded. The treatment end point was when the first return nasogastric fluid was clear and patient hemodynamically stable. Thirteen patients who received continuous infusion of octreotide in 18 episodes of UGI bleeding were included in the study.

On statistical analysis, descriptive data are presented with mean \pm standard deviation, unless otherwise noted. Repeated variables were analyzed using one

Table 1

Diagnosis of all patients during 18 encounters

\begin{tabular}{lc}
\hline Diagnosis & $\begin{array}{c}\text { Number of } \\
\text { patients }\end{array}$ \\
\hline Portal venous thrombosis & 5 \\
Cavernous transformation of portal vein & 2 \\
Congenital hepatic fibrosis & 2 \\
Biliary atresia status post liver & 1 \\
$\quad$ transplantation & 1 \\
Cirrhosis & 1 \\
Alpha-1-antitrypsin deficiency & 1 \\
Prehepatic portal hypertension; status & 1 \\
$\quad$ post spleno-renal shunt & \\
\hline
\end{tabular}

way ANOVA. Paired t-test was used to analyze preand post-octreotide infusion data. A $P$ value of $<0.05$ was considered significant.

\section{Results}

The data from 18 episodes of UGI bleeding in 13 patients were analyzed. Seven patients were male and six female. The mean age of patients was $9.89 \pm$ $6.59 \mathrm{yr}$; range 5 mo to $21 \mathrm{yr}$. The mean body weight of patients was $30 \pm 15.77 \mathrm{~kg}$; range 6.5 to $49.4 \mathrm{~kg}$. Eight patients were transferred from other wards in our own hospital, while five were transported from other institutions. The underlying primary diagnoses, at the time of admission, are given in table 2 .

All 13 patients had portal hypertension. There was a history of prior UGI bleed in preceding 14 episodes. Six patients had undergone sclerotherapy, either once or multiple times in past. One patient had splenic vein embolization done before admission. In all except four episodes, patients were treated with either $\mathrm{H} 2$ blockers or proton pump inhibitors based on discretion of admitting emergency room physician. Ultrasonographic examination of the hepato-biliary system was performed on five patients, revealing partial vein obstruction (two), total obstruction with no evidence of portal vein flow (one), cavernous portal vein (one) and reversal of flow (one). Endoscopy was performed on eight patients. The results are shown in table 3 .

Red cell transfusions were administered during 12 encounters, before or just at the start of octreotide therapy; some episodes also required platelets $(n=3)$ or fresh frozen plasma transfusions $(n=5)$. Recurrent bleeding during octreotide infusion occurred in six episodes requiring red cell transfusions in two of those. A Sangstaken-Blakemore tube was used during one episode of UGI bleeding, to achieve initial hemostasis. No immediate or late complication was observed with its use.

Octreotide infusion was administered for 4 to 392 hours, with a median duration of 28 hours. A loading dose of $1.27 \pm 0.76 \mu \mathrm{g} / \mathrm{kg}$ was used in seven encounters. A starting median initial dose of $1.44 \pm 1.19 \mu \mathrm{g} / \mathrm{kg} / \mathrm{h}$ of octreotide was given as continuous infusion in all other encounters. The infusion was continued with the mean maximum dose of $1.68 \pm 1.38 \mu \mathrm{g} / \mathrm{kg} / \mathrm{h}$ in all episodes. The mean dose at the time of discontinuing the drug had decreased to $0.86 \pm 0.73 \mu \mathrm{g} / \mathrm{kg} / \mathrm{h}$. The mean octreotide dose at the start of the infusion was calculated 
Table 2

Hemodynamic and laboratory values at the beginning, during and at the end of octreotide infusion

\begin{tabular}{|c|c|c|c|c|}
\hline Variables & $\begin{array}{l}\text { Start of octreotide } \\
\text { infusion }\end{array}$ & On octreotide infusion & $\begin{array}{c}\text { End of octreotide } \\
\text { infusion }\end{array}$ & $P$ \\
\hline Heart rate $(\mathrm{bpm})$ & $114 \pm 30$ & $109 \pm 26$ & $97 \pm 19$ & $0.02 *$ \\
\hline Systolic blood pressure (mmHg) & $111 \pm 18$ & $103 \pm 18$ & $106 \pm 14$ & Not significant \\
\hline Diastolic blood pressure $(\mathrm{mmHg})$ & $55 \pm 20$ & $59 \pm 15$ & $57 \pm 13.5$ & $<0.05^{* *}$ \\
\hline Mean arterial pressure $(\mathrm{mmHg})$ & $71 \pm 18$ & $75 \pm 15$ & $73 \pm 11$ & $<0.05^{* *}$ \\
\hline Hemoglobin $(\mathrm{g} / \mathrm{dL})$ & $9 \pm 2.8$ & $10 \pm 1.8$ & $11 \pm 1.5$ & Not significant \\
\hline Platelets $\left(/ \mathrm{mm}^{3}\right)$ & $102.000 \pm 59.000$ & $121 \pm 62$ & $110 \pm 45$ & Not significant \\
\hline Prothrombin time $(\mathrm{sec})$ & $14 \pm 1.6$ & $14 \pm 1.1$ & $14 \pm 0.6$ & Not significant \\
\hline Partial thromboplastin time (sec) & $26.8 \pm 6.18$ & $28.8 \pm 6.8$ & $27.4 \pm 2.7$ & Not significant \\
\hline Total bilirubin $(\mathrm{mg} / \mathrm{dL})$ & $1.46 \pm 0.66$ & $2.56 \pm 0.99$ & $2.8 \pm 1.3$ & Not significant \\
\hline Blood glucose (mg/dL) & $117 \pm 58$ & $115 \pm 19$ & $90 \pm 14$ & Not significant \\
\hline Serum sodium $(\mathrm{mEq} / \mathrm{L})$ & $138 \pm 3.4$ & $139 \pm 2.5$ & $139 \pm 4.5$ & Not significant \\
\hline Blood urea nitrogen $(\mathrm{mg} / \mathrm{dL})$ & $19.5 \pm 16.5$ & $7.6 \pm 3.2$ & $8.2 \pm 3.6$ & Not significant \\
\hline Alanine aminotransferase (IU/L) & $59 \pm 45$ & $63.60 \pm 50.12$ & $66.25 \pm 55.27$ & $<0.05^{*}$ \\
\hline
\end{tabular}

*Start vs. end of infusion.

**Start vs. during infusion.

Table 3

Diagnoses and findings on endoscopy in eight patients

\begin{tabular}{lc}
\hline Peri-hepatic portal hypertension & No findings \\
\hline $\begin{array}{l}\text { Cirrhosis } \\
\text { Portal vein thrombosis and portal } \\
\text { hypertension }\end{array}$ & $\begin{array}{c}\text { Cobblestone appearance } \\
\text { Varices }\end{array}$ \\
$\begin{array}{l}\text { Upper gastrointestinal bleed of } \\
\text { unknown etiology }\end{array}$ & No findings \\
$\begin{array}{l}\text { Portal vein thrombosis and portal } \\
\text { hypertension }\end{array}$ & Varices \\
$\begin{array}{c}\text { Portal vein thrombosis and portal } \\
\text { hypertension }\end{array}$ & Varices \\
$\begin{array}{c}\text { Status post liver transplant for } \\
\text { biliary atresia }\end{array}$ & Varices \\
$\begin{array}{c}\text { Congenital hepatic fibrosis and } \\
\text { portal hypertension }\end{array}$ & Varices \\
\hline
\end{tabular}

as the average of the first hour octreotide infusion rate. The mean octreotide dose at the end of infusion was calculated as the average of the last hour of the infusion before discontinuing it. The hemodynamic and laboratory values at the beginning, during and at the end of all octreotide treatments periods are presented in table 2.

Heart rate significantly decreased from start to the end of octreotide infusion $(P<0.02)$, while the systolic blood pressure showed no significant change. However, diastolic blood pressure and mean arterial pressure were significantly higher during the infusion as compared to their levels before the infusion $(P<0.05)$.

Hemoglobin remained stable during the period of octreotide infusion; while thrombocytopenia (platelet count $<100,000 / \mathrm{mm}^{3}$ ) was observed in 10 of 18 episodes before the start of octreotide, and was relatively unresponsive to platelet infusion therapy. Hyperglycemia (blood glucose level $>120 \mathrm{mg} / \mathrm{dL}$ ) was noted in two patients after the start of octreotide infusion; this however resolved as infusion continued. Blood urea nitrogen decreased significantly $(P<0.05)$, while all other laboratory values remained unchanged during the infusion. The median volume of blood transfusion from the time of admission to the end of octreotide infusion was $17.94 \mathrm{~mL} / \mathrm{kg}$ (range $300 \mathrm{~mL}$ to $1,500 \mathrm{~mL}$ ).

During 12 episodes, patients achieved complete hemostasis and hemodynamic stability on octreotide alone. In six encounters, after achieving initial hemostasis in the unit, the patients needed long-term management procedures such as, transjugular intrahepatic portosystemic shunt or portocaval shunt surgery.

\section{Discussion}

Severe UGI bleeding is a relatively uncommon clinical problem in children and adolescents. Here, we report 18 encounters of UGI bleeding in a cohort of 13 pediatric patients; all were a consequence of portal hypertension. The management of UGI bleeding in pediatrics has been based mostly on adult experience. Vasoactive therapies with vasopressin, somatostatin and octreotide are effective in the emergency control of the bleed [1-4], that includes bleeding from esophageal varices [10-17]. Octreotide use in such pediatric patients has thus far been reported in total of 69 episodes in 53 patients [6-9]. 
Eroglu et al. [7] reported a series of 35 episodes of UGI bleed in 21 patients with portal hypertension, who were treated with an octreotide infusion (loading dose $1-2 \mu \mathrm{g} / \mathrm{kg} / \mathrm{h}$ ), followed by, a continuous infusion (1-2 $\mu \mathrm{g} / \mathrm{kg} / \mathrm{h}$ ) for a duration of 19 hours to 1 week. Authors suggested that without the intrinsic liver disease the response to octreotide might be better with lower mortality.

In our study, octreotide infusion effectively controlled UGI bleeding in all patients. Although recurrent bleeding during octreotide administration was noted $(n=6)$, hemostasis was eventually achieved in all without any additional interventions. Bleeding following endoscopy occurred in one patient and was successfully controlled with octreotide infusion. There is not sufficient data to recommend a definitive octreotide dosing for the control of acute pediatric UGI bleeding. The dosing schedules published in prior studies include: (a) a loading dose of $1 \mu \mathrm{g} / \mathrm{kg}$ followed by continuous infusion of $1 \mu \mathrm{g} / \mathrm{kg} / \mathrm{h}$ [6], (b) a loading dose of $1.66 \pm 0.27 \mu \mathrm{g} / \mathrm{kg}$ followed by a continuous infusion of $2.06 \pm 0.86 \mu \mathrm{g} / \mathrm{kg} / \mathrm{h}$ [9], and (c) a loading dose of 1 to $2 \mu \mathrm{g} / \mathrm{kg}$ followed by infusion of 1 to $2 \mu \mathrm{g} / \mathrm{kg} / \mathrm{h}$ [7]. In our cohort, the bolus and the continuous infusion dose of octreotide used was similar to that of above mentioned studies.

No immediate or short term side effects were observed with use of octreotide in the present series; however, thyroid function tests were not done in the patient who needed prolonged infusion (432 hours). Based on the cumulative data and our own observations, we recommend that octreotide can be used as bolus of $2 \mu \mathrm{g} / \mathrm{kg}$ followed by continuous infusion of $1 \mu \mathrm{g} / \mathrm{kg} / \mathrm{h}$. The maximum dose should be titrated to achieve the desired effect i.e., cessation of UGI bleeding.

The duration of octreotide infusion for UGI bleeding has been previously reported to be as short as 3 hours and as long as 36 days [7], which is similar to our own observations. The decrease in heart rate and stability in systolic blood pressure is probably a consequence of hemorrhage control and intravascular volume repletion. The increase in diastolic and mean arterial blood pressure during octreotide infusion may be direct effect of the medication.

The published pediatric data [6-9] suggests a decrease in the requirements of blood products after initiation of octreotide therapy. Eroglu et al. [7] report a $71 \%$ rate of bleeding control in the group with portal hypertension with $21 \mathrm{~mL} / \mathrm{kg}$ of packed red cells used during the medication infusion; similar to what we observed in this study $(17.94 \mathrm{~mL} / \mathrm{kg})$. Further, in the present series, the need for red cell transfusion was required in only two episodes after the start of octreotide therapy, as compared to 12 episodes before the start of the therapy.

Clinically, no significant adverse event was observed in the present study, or in all the published pediatric data. The only adverse event we observed was transient hyperglycemia in two patients, similar to other reports [9]. It is speculated that octreotide may be associated with the hyperglycemia because of anti insulin effect [18]. Zellos and Schwarz [8] administered a high dose of octreotide ( 4 to $8 \mu \mathrm{g} / \mathrm{kg} / \mathrm{h}$ ) for therapy of severe chronic UGI bleeding for prolonged periods of time (24 to 50 months). They noticed a decrease in linear growth velocity and laboratory evidence of hypothyroidism in one patient. They also did cost benefit analysis showing that the total cost of octreotide infusion was half of that of blood transfusions; without factoring in the innate risks of blood product transfusions. One of our patients received octreotide infusion for 3 weeks, with no apparent effect on his thyroid function. However, the patient was not followed for long-term effects on his linear growth.

Octreotide infusion therapy achieves hemostasis in $80 \%$ of adult patients with acute UGI bleeding due to portal hypertension $[11,12,15,16]$. Both in our study and in the previous report [7], very effective hemostasis was achieved in children with acute UGI bleeding secondary to similar etiopathology following the initiation of continuous octreotide therapy. Randomized controlled studies are a difficult clinical undertaking in this situation because of the intrinsic heterogeneity of the etiologies causing the UGI bleed [9]. We conclude, based on our data and other similar observational studies, that continuous octreotide infusion, in children, is safe and effective in controlling acute UGI bleed; including that due to portal hypertension. While octreotide may decrease the blood product requirements, it may be used either for definitive management or as a bridge to invasive management. Most of the patients in our study had extra hepatic portal hypertension. This fact should be taken into account before applying the results of this study to a large population. We recommend, because of excellent therapeutic profile, a continuous octreotide infusion, which may be initiated at the referring community or rural hospital prior to transfer of such patients to a tertiary care facility. 


\section{References}

[1] Corley DA, Cello JP, Adkisson W, Ko WF, Kerlikowske K. Octreotide for acute esophageal variceal bleeding: a metaanalysis. Gastroenterology 2001;120(4):946-54.

[2] Sung JJ, Chung SC, Lai CW Chan FK, Leung JW, Yung MY, et al. Octreotide infusion or emergency sclerotherapy for variceal haemorrhage. Lancet 1993;342(8872):637-41.

[3] Jenkins SA, Baxter JN, Critchley M Kingsnorth AN, Makin CA, Ellenborg S, et al. Randomised trial of octreotide for long term management of cirrhosis after variceal haemorrhage. BMJ 1997;315:1338-41.

[4] Jenkins SA, Poulianos G, Coraggio F, Rotondano G. Somatostatin in the treatment of non-variceal upper gastrointestinal bleeding. Dig Dis 1998;16(4):214-24.

[5] Mosdell KW, Visconti JA. Emerging indications for octreotide therapy, Part 2. Am J Hosp Pharm 1994;51(10):1317-30.

[6] Lam JC, Aters S, Tobias JD. Initial experience with octreotide in the pediatric population. Am J Ther 2001;8(6): 409-15.

[7] Eroglu Y, Emerick KM, Whitingon PF, Alonso EM. Octreotide therapy for control of acute gastrointestinal bleeding in children. J Pediatr Gastroenterol Nutr 2004;38(1):41-7.

[8] Zellos A, Schwarz KB. Efficacy of octreotide in children with chronic gastrointestinal bleeding. J Pediatr Gastroenterol Nutr 2000;30(4):442-6.

[9] Siafakas C, Fox VL, Nurko S. Use of octreotide for the treatment of severe gastrointestinal bleeding in children. J Pediatr Gastroenterol Nutr 1998;26(3):356-9.

[10] D'Amico G, Pietrosi G, Tarantino I, Pagliaro L. Emergency sclerotherapy versus vasoactive drugs for variceal bleeding in cirrhosis: a Cochrane meta-analysis. Gastroenterology 2003;124(5):1277-91.
[11] Shah HA, Mumtaz K, Jafri W, Abid S, Hamid S, Ahmad A, et al. Sclerotherapy plus octreotide versus sclerotherapy alone in the management of gastro-oesophageal variceal hemorrhage. J Ayub Med Coll Abbottabad 2005;17(1):10-4.

[12] Zhou Y, Qiao L, Wu J, Hu H, Xu C. Comparison of the efficacy of octreotide, vasopressin, and omeprazole in the control of acute bleeding in patients with portal hypertensive gastropathy: a controlled study. J Gastroenterol Hepatol 2002;17(9):973-9.

[13] Freitas DS, Sofia C, Pontes JM, Gregorio S, Cabral JP, Andrade $\mathrm{P}$, et al. Octreotide in acute bleeding esophageal varices: a prospective randomized study. Hepatogastroenterology 2000;47(35):1310-4.

[14] Bildozola M, Kravetz D, Argonz J, Romero G, Suarez A Jmelnitzky A, et al. Efficacy of octreotide and sclerotherapy in the treatment of acute variceal bleeding in cirrhotic patients. A prospective, multicentric, and randomized clinical trial. Scand J Gastroenterol 2000;35(4):419-25

[15] Zuberi BF, Baloch Q. Comparison of endoscopic variceal sclerotherapy alone and in combination with octreotide in controlling acute variceal hemorrhage and early rebleeding in patients with low-risk cirrhosis. Am J Gastroenterol 2000;95(3):768-771.

[16] Jenkins SA, Shields R, Davies M, Elias E, Turnbull AJ, Bassendine MF, et al. A multicentre randomised trial comparing octreotide and injection sclerotherapy in the management and outcome of acute variceal haemorrhage. Gut 1997; 41(4):526-33.

[17] Besson I, Ingrand P, Person B, Boutroux D, Heresbach D, Bernard P, et al. Sclerotherapy with or without octreotide for acute variceal bleeding. N Engl J Med 1995;333(9): 555-60.

[18] Lamberts SW, van der Lely AJ, de Herder WW, Hofland LJ. Octreotide. N Engl J Med 1996;334(4):246-54. 